\title{
ANALISIS TINGKAT PENGETAHUAN IBU RUMAH TANGGA TENTANG JENIS DAN BAHAYA PLASTIK KEMASAN MAKANAN DI WILAYAH KERJA PUSKESMAS SUNGAI BESAR KOTA BANJARBARU TAHUN 2012
}

\author{
Isnawati \\ Poltekkes Kemenkes Banjarmasin Jurusan Kesehatan Lingkungan Banjarbaru \\ Jl. H. Mistar Cokrokusumo No. 1A Kota Banjarbaru \\ e-mail : isna.husaini1@gmail.com
}

\begin{abstract}
Analysis Of Knowledge About The Housewife And Dangers Of Plastic Food Packaging In The Region "Puskesmas Sungai Besar" Banjarbaru Cyty In 2012. Banjarbaru ranks second in South Kalimantan in terms of degenerative diseases (RISKESDA, 2007). Not a few in this town of outstanding products especially plastic packaging used for food, how did the mother know the type of plastic household and trying to protect their families from products that endanger the health of their families. This study aims to determine the level of knowledge about the type Housewife and Hazard plastic food packaging in the region of the Puskesmas Sungai Besar Banjarbaru City with methods of descriptive and cross-sectional approach, the 68 housewives. Education levels housewife in Puskesmas Sei. Besar 44.1\% had graduated from high school. Sources of information about the types of food packaging $51.5 \%$ came from television and radio, and the other from a friend, neighbor, print media and school/ college. Housewife knowledge about the dangers of plastic food packaging $75 \%$ of the radio and television and on the type of plastic food packaging low. Only 1.5\% who know the type of plastic in the market. Plastics are not eligible yet many (54.5\%) are known to housewives. The level of knowledge Housewife In Puskesmas Sei. Besar about the type of food packaging mostly low, so about the dangers of plastics used as food packaging. Types of plastics for food packaging are widely circulated, still wise in choosing the type of plastic to avoid the danger caused.
\end{abstract}

Keywords: plastic; knowledge; danger; packaging

\begin{abstract}
Abstrak : Analisis Tingkat Pengetahuan Ibu Rumah Tangga Tentang Jenis dan Bahaya Plastik Kemasan Makanan di Wilayah Kerja Puskesmas Sungai Besar Kota Banjarbaru Tahun 2012. Banjarbaru menempati urutan ke dua di Kalimantan Selatan dalam hal penyakit degenerative (RISKESDA,2007). Tidak sedikit di kota ini produk beredar terutama kemasan plastik yang digunakan untuk makanan, seberapa tahukah ibu rumah tangganya mengenal jenis plastik dan berusaha melindungi keluarganya dari produk yang membahayakan kesehatan keluarganya. Penelitian ini bertujuan untuk mengetahui Tingkat Pengetahuan Ibu Rumah Tangga tentang Jenis dan Bahaya plastik kemasan makanan di wilayah kerja Puskesmas Sungai Besar Kota Banjarbaru dengan metode deskriftif dan pendekatan cross sectional, pada $68 \mathrm{ibu}$ rumah tangga. Tingkat pendidikan ibu rumah tangga di Wilayah Kerja Puskesmas Sei. Besar 44.1\% sudah lulus SMU. Sumber informasi tentang jenis plastik kemasan makanan $51,5 \%$ berasal dari televisi dan radio, dan yang lainnya dari teman, tetangga, media cetak dan bangku sekolah/kuliah. Pengetahuan ibu rumah tangga tentang bahaya plastik kemasan makanan 75\% dari radio dan televise. Pengetahuan tentang jenis plastik kemasan makanan rendah. Hanya 1,5\% yang tahu jenis plastik yang beredar dipasaran. Plastik yang tidak memenuhi syarat belum banyak (54,5\%) diketahui oleh ibu rumah tangga. Tingkat pengetahuan Ibu Rumah Tangga Di Wilayah Kerja Puskesmas Sei. Besar tentang jenis plastik kemasan makanan sebagian besar rendah, demikian tentang bahaya plastik yang digunakan sebagai kemasan makanan. Jenis plastik untuk kemasan makanan yang banyak beredar, tetaplah bijaksana dalam memilih jenis plastik agar terhindar dari bahaya yang ditimbulkannya.
\end{abstract}

Kata kunci: plastik; pengetahuan; bahaya; kemasan

\section{PENDAHULUAN}

Riset epidemiologi mengalami kemajuan pesat dan pola penyakit mulai bergeser dari penyakit infeksi kepenyakit kronis dan generatif. Seperti riset Doll dan Hill, 1950 yang meneliti hubungan kanker 
paru dan merokok pada awal tahun 1950 an, demikian juga dengan penelitian Kannel, 1990 yang mengeksplorasi faktor risiko penyakit jantung coroner (Murti, 2003). Mulai bermunculannya penyakit seperti kanker sebagai penyakit degenerative sudah terdeteksi seperti yang ditunjukan pada hasil survey RISKESDA Provinsi Kalimantan Selatan tahun 2007, prevalensi penyakit tumor atau orang yang pernah didiagnosis menderita tumor/kanker adalah 3,5\%o dan sebagian besar berusia $>5$ tahun. Kota Banjarbaru berada di urutan ke dua dengan prevalensi 8,8 \%o atau berada di atas ratarata Kalimantan Selatan (Kalsel, 2008).

Banyak faktor risiko yang memungkinkan timbulnya penyakit degenerative, diantaranya makanan yang dikonsumsi dapat saja tercemar baik oleh bakteriologis, maupun kimia termasuk yang berasal dari kemasan yang digunakan. Kemasan sebenarnya berfungsi untuk membantu dan mencegah atau mengurangi terjadinya kerusakan pada makanan (Nurminah, 2002) Wadah atau kemasan yang paling popular sekarang adalah plastik dan sering digunakan untuk wadah atau kemasan makanan dan minuman dalam rumah tangga dari bungkus sampai peralatan yang ada di rumah tangga (Koswara, 2006). Kemasan plastik mulai diperkenalkan pada tahun 1900an. Sejak itu perkembangannya sangat cepat. Sesudah Perang Dunia II diperkenalkan berbagai jenis kemasan plastik dalam bentuk kemasan lemas (fleksibel) maupun kaku. Beberapa jenis kemasan plastik yang dikenal antara lain polietilen, polipropilen, polyester, nilon serta vinil film. Bahkan selama dua dasawarsa terakhir, pangsa pasar dunia untuk kemasan pangan telah direbut oleh kemasan plastik, Penggunaan plastik (Koswara, 2006). Untuk kemasan makanan sudah meluas bahkan sudah menjangkau desa-desa terpencil. Harganya relative murah dan praktis, sehingga mampu menyisihkan bahan pembungkus makanan alami seperti daun pisang, daun jati dan daun kelapa muda (Hidayat). Walaupun banyak keunggulan dari kemasan plastik kenapa menjadi pilihan, tetapi perlu juga diperhatikan kelemahannya diantaranya adalah kemungkinan ter- jadinya migrasi atau berpindahnya zat-zat monomer dari bahan plastik ke dalam makanan, terutama jika makanan tersebut tak cocok dengan kemasan atau wadah penyimpannya, dan dapat merusak lingkungan.

Bahaya zat kimia yang sering dipakai dalam bahan pembuat plastik sudah sejak lama diperdebatkan. Meski belum dilarang tapi sebagian ahli menganggap paparannya terutama bisphenol_A (BPA) berbahaya untuk kesehatan, terlebih pada perilaku anak-anak. Studi terbaru menyebutkan gangguan perilaku yang dialami balita perempuan usia 3 tahun, seperti kecemasan dan agresivitas, diduga kuat dipengaruhi oleh BPA yang dialami wanita selama kehamilan. Menurut hasil studi terbaru yang dilakukan di Amerika Serikat, peneliti Harvard mengambil urin ibu hamil yang tinggal di Cincinnati (Anna). Bahkan Badan Pengawas Obat dan makanan RI (BPOM, 2009) dengan peringatan bernomor : KH.00.02.1.55.2890 tanggal 14 Juli 2009 mengeluarkan Peringatan/public warning tentang kantong plastik "kresek" terutama berwarna hitam merupakan produk daur ulang yang sering digunakan untuk mewadahi makanan. Sosialisasi bahaya penggunaan kemasan plastik menurut Anna (2011) sudah banyak, terutama dalam memberi peringatan, rumor bahkan artikel tentang bahaya plastik. Tetapi hanya segelintir orang yang peduli atau sampai meneliti lebih lanjut. Pengetahuan masyarakat tentang jenis plastik dan bahayanya memang perlu perhatian khusus dari berbagai pihak, terutama bagi ibu rumah tangga yang banyak tahu tentang kebutuhan di dalam rumah tangga terutama dalam hal menjaga generasi yang akan datang sehingga pencapaian derajat kesehatan masyarakat yang lebih baik menjadi titik perhatian kita.

Banjarbaru menempati urutan kedua di Kalimantan Selatan dalam hal penyakit degenerative (RISKESDA,2007). Tidak sedikit di kota ini produk beredar terutama kemasan plastik yang digunakan untuk makanan, seberapa tahukah ibu rumah tangganya mengenal jenis plastik dan berusaha melindungi keluarganya dari produk yang membahayakan kese- 
hatan keluarganya. Penelitian ini bertujuan untuk mengetahui Tingkat Pengetahuan Ibu Rumah Tangga tentang Jenis dan Bahaya plastik kemasan makanan di wilayah kerja Puskesmas Sungai Besar Kota Banjarbaru.

\section{Kerangka Teori}

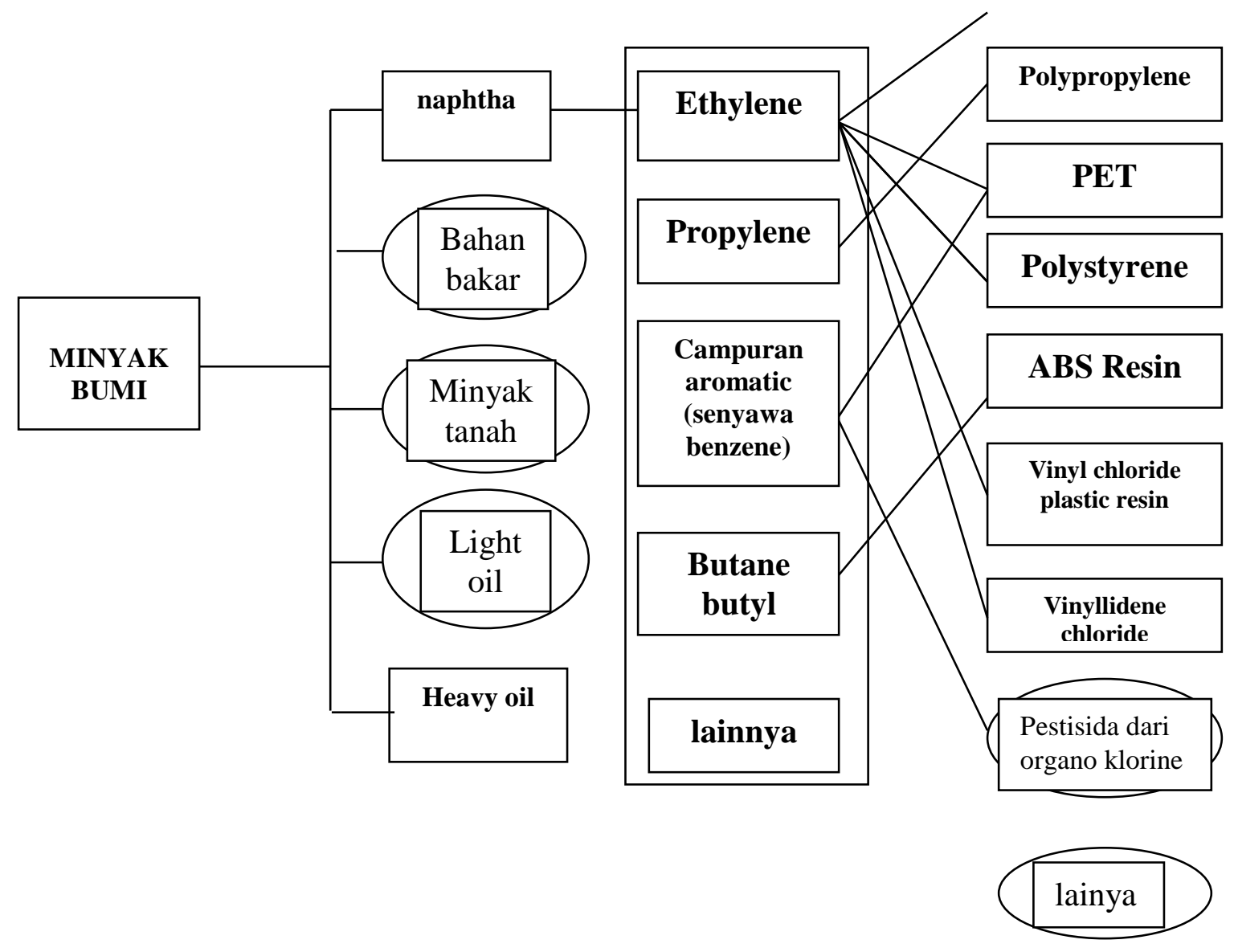

Plastik mengandung chlorin yang melepaskan dioxins, sebuah racun yang mematikan bila dibakar, lebih lanjut beberapa pastik melepaskan kandungankandungan yang mengganggu sistem hormon tubuh (mengganggu system endokrin) saat dikubur sebagai sampah. Plastik yang dapat digunakan adalah yang tidak mengandung chlorin yang sering digunakan sebagai bahan bakar. Penggunaan plastik sebagai bahan pengemas mempunyai keunggulan dibanding bahan pengemas lain karena sifatnya yang ringan, transparan, kuat, termoplatis dan selektif dalam permeabilitasnya terhadap uap air, $\mathrm{O}_{2}, \mathrm{CO}_{2}$. Sifat permeabilitas plastik terhadap uap air dan udara menyebabkan plastik mampu berperan memodifikasi ruang kemas selama penyimpanan
(Winarno, 1987). Ryall dan Lipton (1972) menambahkan bahwa plastik juga merupakan jenis kemasan yang dapat menarik selera konsumen.

\section{METODE PENELITIAN}

Jenis Penelitian yang dilakukan adalah deskriftif dengan pendekatan cross sectional mempelajari Penelitian dilaksanakan di Puskesmas Sei. Besar Kota Banjarbaru yang dijadikan lokasi penelitian dari September 2011 sampai dengan Agustus 2012 dengan populasi adalah semua ibu rumah tangga yang ke Puskesmas Sei. Besar Kota Banjarbaru dengan kriteria; 1) Memiliki anak balita/bayi, 2) Bersedia menjadi responden, 3) Minimal bisa baca tulis/tidak buta huruf, karena populasinya belum diketahui maka dila- 
kukan perkiraan besar sampel dengan alpha $10 \%$, presisi 0,1 dan proporsi pengetahuan ibu rumah tangga yang tahu dan tidak tahu diasumsikan 50\%, maka dengan rumus sampel estimasi proporsi dari S.K. Lwanga \& S. Lemeshow (WHO)

$$
\mathrm{n}=\frac{z_{1-x / s}^{2} \mathrm{P}(1-\mathrm{P})}{\mathrm{d}^{2}}
$$

, maka sampel berjumlah 68 ibu rumah tangga. Variabel Penelitian adalah tingkat Pengetahuan Ibu Rumah Tangga yang Hasil Tahu ibu rumah tangga yang memiliki bayi/balita tentang jenis dan bahaya kemasan yang terbuat dari plastik di Wilayah kerja Puskesmas Sei. Besar dengan mengguna- kan kuesioner dan dikategorikan menjadi Tinggi (76-100\% benar), Sedang (56$100 \%$ benar), Rendah $(<56 \%)$. Data dikumpulkan dengan cara Wawancara dan pengisian kuesioner tentang pengetahuan ibu rumah tangga tentang jenis dan bahaya plastik sebagai kemasan makanan, dan dianalisis secara deskriftif.

\section{HASIL PENELITIAN}

Umur

Ibu rumah tangga yang memiliki anak bayi dan balita di Wilayah kerja Puskesmas Sei. Besar sebagian besar berusia antara 30-39 tahun dan dapat dilihat pada tabel 1.

Tabel 1. Kelompok Umur Ibu Rumah Tangga di Wilayah Kerja Puskesmas Sei. Besar tahun 2012

\begin{tabular}{clcc}
\hline No & \multicolumn{1}{c}{ Kelompok Umur } & Frekuensi & Persen \\
\hline 1. & $<20$ tahun & 0 & 0 \\
2. & $20-29$ tahun & 22 & 32.4 \\
3. & $30-39$ tahun & 35 & 51.5 \\
4. & $40-49$ tahun & 9 & 13.2 \\
5. & $>50$ tahun & 2 & 2.9 \\
\hline & Total & 68 & 100.0 \\
\hline
\end{tabular}

\section{Pekerjaan}

Tabel 2 Menunjukan sebagian besar

rumah tangga, hanya 10,3 \% yang bekerja sebagai Pegawai Negeri sipil. $(76,5 \%)$ pekerjaan responden adalah ibu

Tabel 2. Pekerjaan Ibu Rumah Tangga di Wilayah Kerja Puskesmas Sei. Besar Tahun 2012

\begin{tabular}{clcc}
\hline No & Pekerjaan & Frekuensi & Persen \\
\hline 1. & PNS & 7 & 10.3 \\
2 & Swasta & 9 & 13.2 \\
3 & Ibu rumah tangga & 52 & 76.5 \\
\hline \multicolumn{2}{l}{ Total } & 68 & 100 \\
\hline
\end{tabular}

\section{Jumlah anggota keluarga}

Keluarga inti yang terdiri dari ayah, ibu dan dua orang anak merupakan bagian terbesar dari jumlah keluarga di wilayah kerja Puskesmas Sei. Besar yaitu $69,1 \%$, selebihnya adalah termasuk keluarga besar.

Tabel 3. Jumlah Anggota Keluarga di Wilayah Kerja Puskesmas Sei. Besar Tahun 2012

\begin{tabular}{cccc}
\hline No & Anggota Keluarga & Frekuensi & Persen \\
\hline 1. & < atau = 4 orang & 47 & 69.1 \\
2. & $>4$ orang & 21 & 30.9 \\
\hline
\end{tabular}




\begin{tabular}{lcc}
\hline Total & 68 & 100 \\
\hline
\end{tabular}

Lumlah bayi dan balita

Jumlah bayi dan balita dalam keluarga sebagian besar kurang dari dan sama dengan 2 orang berjumlah 61 Responden atau 89,7\%, seperti yang ada pada tabel 4. berikut :

Tabel 4. Jumlah Bayi dan Balita di Keluarga di Wilayah Kerja Puskesmas Sei. Besar

\begin{tabular}{clcc}
\hline No & Bayi dan Balita & Frekuensi & Persen \\
\hline 1 & $<$ atau $=2$ orang & 61 & 89.7 \\
2 & $>2$ orang & 7 & 10.3 \\
\hline Total & 68 & 100 \\
\hline
\end{tabular}

\section{Tingkat Pendidikan Ibu Rumah Tangga}

Tingkat pendidikan ibu rumah tangga di Wilayah Kerja Puskesmas Sei. Besar sebagian besar $(44.1 \%)$ sudah lulus SMA/
SMU atau tingkat pendidikan menengah, dan masih ada 10,3\% masih memiliki tingkat pendidikan dasar (lulusan SD) yang ditunjukkan pada grafik 1 berikut :

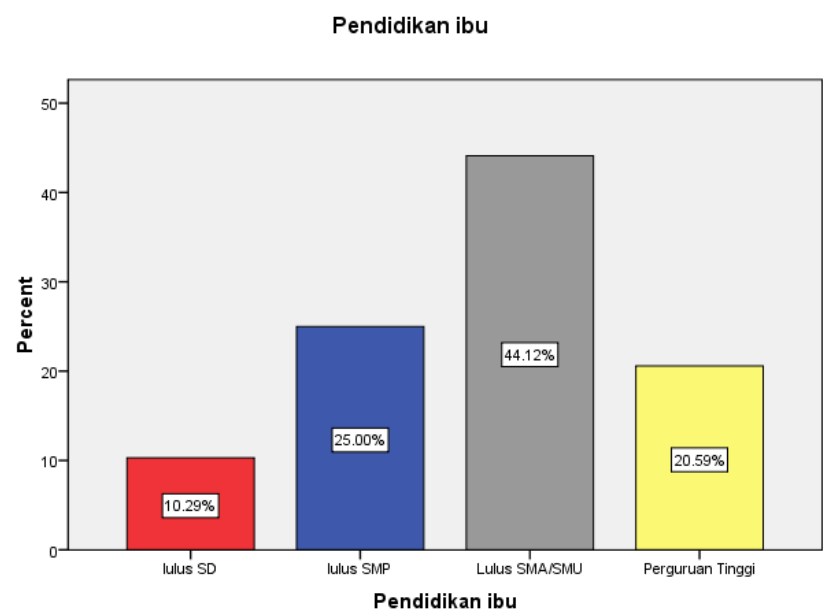

Gambar 1. Tingkat Pendidikan Ibu Rumah Tangga di Wilayah Kerja Puskesmas Sei. Besar Banjarbaru

\section{Media informasi tentang jenis plastik}

Sumber informasi yang didapatkan ibu rumah tangga tentang jenis-jenis plastik kemasan makanan sebagian besar $(51,5 \%)$ adalah berasal dari media televisi dan radio, sedangkan sumber informasi didapatkan dari teman, tetangga, media cetak dan bangku sekolah/kuliah seperti yang ditunjukan pada grafik 2 . 
Sumber Informasi tentang Jenis plastik Kemasan Makanan

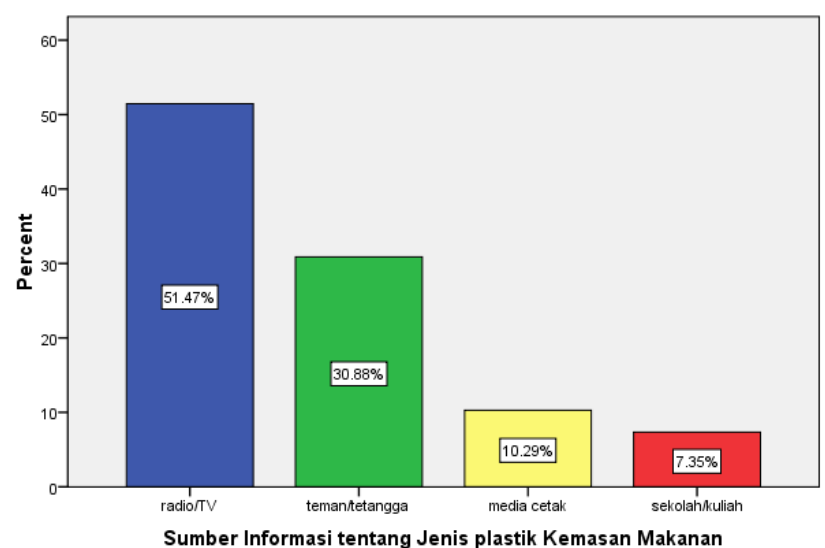

Gambar 2. Sumber Informasi Ibu Rumah Tangga tentang Jenis Plastik Kemasan Makanan di Wilayah Kerja Puskesmas Sei. Besar

\section{Sumber informasi tentang bahaya plas-} $\underline{\text { tik }}$

Pengetahuan ibu rumah tangga tentang bahaya plastik kemasan makanan paling banyak (75\%) diperoleh dari radio dan televisi, sedangkan yang tidak pernah mendapatkan informasi berkisar 11,8\% yang ditunjukan pada grafik 3 . berikut :

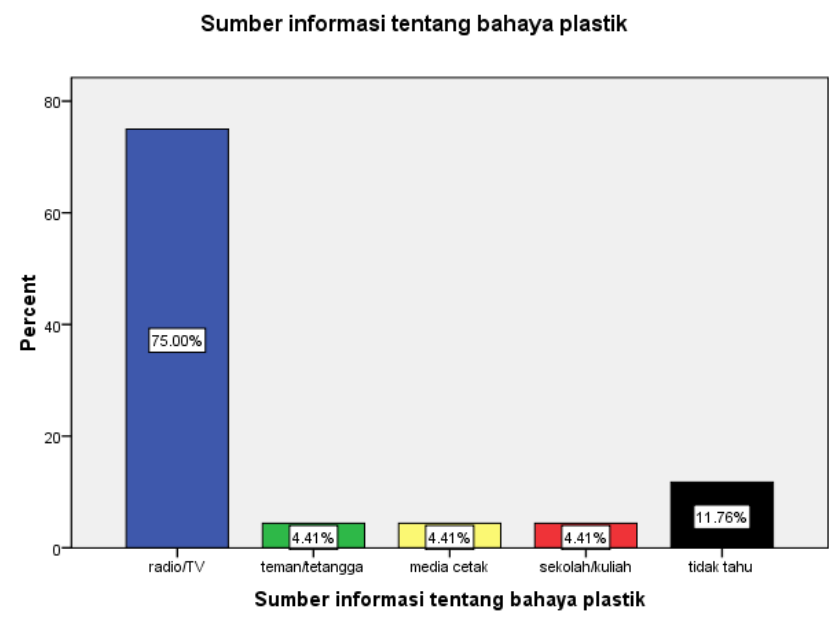

Gambar 3. Sumber Informasi Ibu Rumah Tangga tentang Bahaya plastik Kemasan Makanan di Wilayah Kerja Puskesmas Sei. Besar

Tingkat pengetahuan ibu rumah tangga tentang jenis plastik kemasan makanan

Tingkat pengetahuan ibu rumah tangga tentang jenis plastik kemasan makanan sebagian besar $(61,8 \%)$ rendah dan sangat sedikit $(1,5 \%)$ yang tahu dan mengenal jenis plastik yang beredar dipasaran, terutama mengenal kode plastik yang bisa digunakan untuk makanan. 


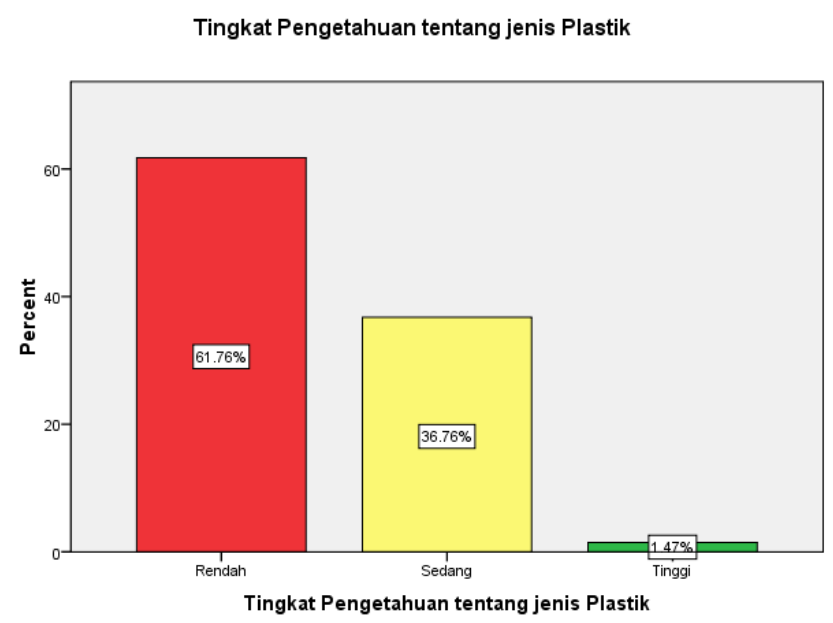

Gambar 4. Tingkat Pengetahuan Ibu Rumah Tangga Tentang Jenis Plastik Kemasan makanan di Wilayah Kerja PKM Sei. Besar

Tingkat pengetahuan ibu rumah tangga tentang bahaya plastik

Bahaya plastik kemasan makanan yang tidak memenuhi syarat belum banyak diketahui oleh ibu rumah tangga sebagai responden seperti pada gambar 5 . dimana 54,5\% atau lebih dari separoh responden memiliki pengetahuan yang rendah tentang bahaya plastik tersebut kalau digunakan sebagai wadah atau kemasan makanan.

Tingkat Pengetahuan tentang bahaya plastik

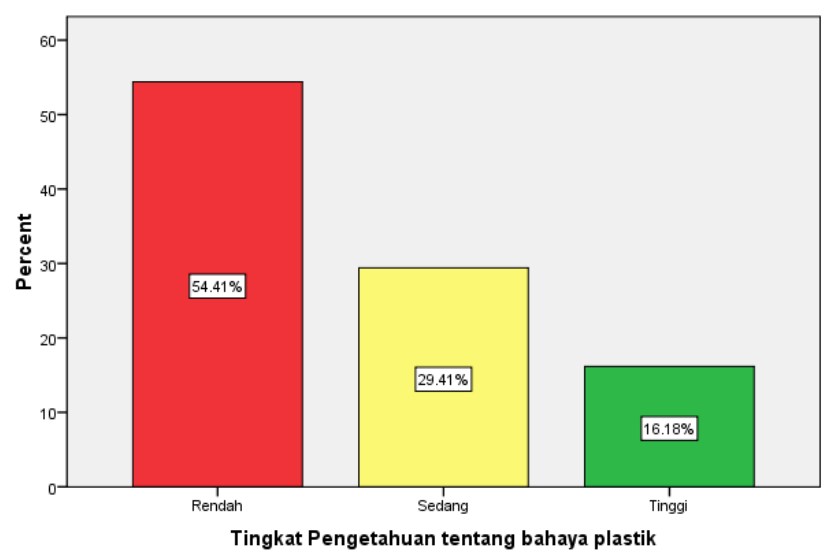

Gambar5. Tingkat Pengetahuan Ibu Rumah Tangga tentang Bahaya Plastik Kemasan Makanan di Wilayah Kerja Puskesmas Sei. Besar

\section{PEMBAHASAN}

\section{Tingkat Pendidikan Ibu Rumah Tangga}

Pendidikan secara umum adalah segala upaya yang direncanakan untuk mempengaruhi orang lain, individu, kelompok, atau masyarakat sehingga mereka melakukan apa yang telah dilakukan oleh pelaku pendidikan. Menurut Wied Heri Apriadji Dalam Zuleha 2010 tingkat pendidikan turut pula menentukan mudah tidaknya seseorang menyerap dan memahami pengetahuan yang mereka peroleh. Berdasarkan tabel 1. tingkat pendidikan ibu rumah tangga di wilayah kerja Puskesmas Sei. Besar sebagian besar adalah setingkat SMA atau pendidikan menengah. Pendidikan juga terkait dengan akses informasi yang didapatkan, 
semakin tinggi pendidikan seseorang maka semakin bisa lebih banyak mendapatkan informasi tentang kesehatan terutama dalam hal ini adalah yang berhubungan dengan jenis dan bahaya plastik kemasan makanan, sehingga mereka lebih memiliki banyak pengetahuan.

\section{Media informasi tentang jenis plastik}

Kemajuan teknologi informasi membawa banyak perubahan terhadap nilai-nilai kehidupan karena informasi dapat mempengaruhi atau menambah pengetahuan seseorang. Sumber informasi bisa berasal dari media cetak, elektronik, billboard maupun dari orang lain (Notoatmojdjo, 2003). Seperti halnya informasi tentang jenis dan bahaya plastik kemasan makanan yang didapatkan oleh ibu rumah tangga di wilayah kerja Puskesmas Sei. Besar banyak didapatkan dari media elektronik seperti radio dan televisi. Tetapi menurut George R berguna tidaknya informasi tergantung pada tujuan ibu rumah tangga tersebut untuk mendapatkannya, waktu, ruang dan tempat, bentuk serta semantik yang harus ada hubungannya antara kata-kata dan arti yang cukup jelas dari kemungkinan salah tafsir.

Tingkat pengetahuan ibu rumah tangga tentang jenis plastik

Tingkat Pengetahuan Ibu Rumah Tangga di Wilayah Kerja Puskesmas Sei. Besar tentang jenis plastik kemasan makanan rata-rata rendah, padahal frekuensi penggunaan plastik sebagai wadah atau kemasan makanan sering mereka gunakan $(32,4 \%)$ dan yang menggunakan walaupun jarang berkisar $63,2 \%$. Alasan penggunaan didominasi kepraktisan di samping mudah didapat. Jenis plastik yang ada dipasaran biasanya memiliki kode yang berada di dasar wadah/ kemasan dan hampir 75\% ibu rumah tangga tidak mengetahui hal tersebut, sehingga dalam memilih jenis plastik cenderung hanya kepraktisan dan mudah didapat saja. Penggunaan kantong plastik kresek juga cenderung menggunakan yang berwarna, padahal menurut Badan Pengawas Obat dan Makanan menyebutkan bahwa kantong plastik kresek berwarna terutama hitam kebanyakan produk daur ulang yang sering digunakan untuk mewadahi makanan dan sebaiknya jangan menggunakannya terutama untuk mewadahi langsung makanan siap santap. Menurut Ulmer (1994) dalam Supadmi, 2000 "Pengetahuan merupakan domain yang sangat penting untuk menumbuhkan tindakan seseorang yang selanjutnya menimbulkan kesadaran dan akhirnya seseorang berprilaku sesuai pengetahuan yang dimilikinya".

Tingkat pengetahuan ibu rumah tangga tentang bahaya plastik kemasan makanan

Plastik kemasan makanan sekarang banyak sekali beredar, baik yang bisa digunakan ataupun yang tidak. Ibu rumah tangga di wilayah ini sebagian besar $(64,7 \%)$ tidak mengetahui hal itu, bahkan untuk dot bayipun masih sangat minim $(19,1 \%)$ yang tahu dan masih salah memilih jenis plastiknya. Studi menunjukkan bahwa botol plastik untuk bayi dapat menimbulkan risiko kesehatan yang serius bagi anak-anak, terutama ketika botol itu dipanaskan agar susu formula di dalamnya menjadi hangat. Proses pemanasan ini melepaskan bahan kimia berbahaya yang berasal dari plastik ke dalam susu formula. Ketika dipanaskan, konsentrasi bisphernol-A yang tinggi dilepaskan. Zat kimia ini bertindak sebagai hormon estrogen yang dapat merubah fungsi sel. Ini diyakini sebagai menyebabkan kanker, ketidaksuburan, masalah tiroid, diabetes tipe 2 dan gangguan belajar.

Makanan yang mengandung lemak tinggi dan yang bersifat sangat asam mudah sekali bereaksi dengan plastic jenis PVC. Menurut hasil sebuah penelitian, sekitar 10-40 ppb monomer vinyl chloride dapat diserap makanan dan minuman yang berlemak dan bersifat asam. Penggunaan plastik sebagai kemasan untuk makanan berlemak dan asam jarang digunakan, hanya sekitar $13,3 \%$ saja, tapi walaupun rendah juga perlu menjadi perhatian. Tidak semua botol plastik boleh dipergunakan kembali. Kebiasaan ibu rumah tangga di wilayah kerja puskesmas Sei. Besar ternyata masih ada (25\%) yang menggunakan botol plastik sampai berkali-kali. Bahaya kesehatan mulai dari iritasi kulit, gangguan hormon, saluran pernapasan hingga kanker, dan bukan hanya 
botol plastik saja yang sebaiknya tidak digunakan berulang. Produk plastik lain seperti wadah makan, penutup makanan hingga botol susu, juga perlu dicermati.

Badan Pengawas Obat-obatan dan Makanan (BPOM) memperingatkan masyarakat, agar tak menggunakan plastik kresek hitam sebagai wadah makanan. Menurut Ketua Badan Husniah Rubiana Thamrin Akib, plastik kresek merupakan produk daur ulang yang sulit diketahui bahan asalnya, demikian juga kresek yang berwarna, menurut BPOM, kantong plastik berwarna sangat berbahaya bagi kesehatan bila digunakan untuk mewadahi makanan siap saji. Plastik tersebut merupakan produk daur ulang yang riwayat penggunaan sebelumnya tidak diketahui secara pasti. Sampah plastik. juga perlu diperhatikan penanganannya, sebagian besar (75\%) ibu rumah tangga membuang atau mengubur sampah plastik padahal dengan dikubur plastik dapat melepaskan kandungan yang mengganggu system endokrin ke dalam tanah.

\section{SIMPULAN}

Ibu rumah tangga di Wilayah kerja Puskesmas Sei Besar berpendidikan setingkat SMU dengan tingkat pengetahuan tentang jenis plastik kemasan makanan sebagian besar rendah, demikian tentang bahaya plastik yang digunakan sebagai kemasan makanan. Sumber informasi yang didapatkan ibu rumah tangga tentang jenis-jenis plastik kemasan makanan sebagian besar adalah berasal dari media televisi dan radio, demikian juga tentang bahaya plastik. Jenis plastik untuk kemasan makanan yang banyak beredar, tetaplah bijaksana dalam memilih jenis plastik agar terhindar dari bahaya yang ditimbulkannya dan perlu ada penyuluhan yang memberikan informasi tentang jenis dan bahaya plastik kemasan makanan, terutama dalam pengenalan kode-kode yang terdapat pada wadah/kemasan plastik tersebut.

\section{DAFTAR PUSTAKA}

1. Badan Pengawas Obat dan Makanan Republik Indonesia, Peringatan/Public warning tentang Kantong Plastik
“Kresek, KH.00.02.1.55.2890 tanggal 14 Juli 2009

2. Departemen Kesehatan RI, Pedoman Pelaksanaan Simulasi, Deteksi dan Intervensi Tumbuh Kembang Anak Di Tingkat Pelayanan Kesehatan Dasar, Jakarta, Depkes RI, 2007

3. Bhisma Murti, Prinsip dan Metode Riset Epidemiologi, Gadjah Mada University Press Yogyakarta, 2007

4. Atep Afia Hidayat, Bahaya Kemasan Plastik,

http://www.pantonanews.com/berita -119-bahaya-kemasan-plastik-html,

19 Januari 2011

5. Sutrisno Koswara, Bahaya di balik Kemasan Plastik, ebookpangancom, 2008.

6. Mimi Nurminah, Penelitian Sifat Berbagai Bahan Kemasan Plastik dan Kertas Serta Pengaruhnya Terhadap Bahan yang Dikemas, USU digital library, 2002.

7. Lusia Kus Anna, Bahaya Plastik BPA pada Wanita Hamil, http://id.shvoong.com.society=andnews/news-item/1839827-bahayaplastik-bagikesehatan/\#ixzz1fA2VliFd, 2011

8. Dinas Kesehatan Provinsi Kalimantan Selatan, Riset Kesehatan Dasar tahun 2007, Banjarmasin, 2008

9. William G. Cochran, Teknik Penarikan Sampel, UI - Press. Jakarta, Edisi ketiga,1991

10. S.K. Lwanga And S. Lemeshow, Sample Size Determination Health Studies, WHO,

11. Anna, L. K. (n.d.). Retrieved 2011

12. BPOM. (2009). Peringatan/Public warning tentang Kantong Plastik. Jakarta: BPOM RI.

13. Depkes. (2007). Pedoman Pelaksanaan Simulasi, Deteksi dan Intervensi Tumbuh Kembang Anak di Tingkat pelayanan Kesehatan dasar. Jakarta: Depkes RI.

14. Zuleha, Hubungan pengetahuan ibu dengan sataus gizi balita usia 6-24 bulan di kelurahan sei Pering Kabupaten Banjar tahun 2010, AKBID Martapura, tahun 2010. 
15. Hidayat, A. A. (n.d.). Bahaya Kemasan Plastik. Retrieved Desember 2011, from

http://www.pantnanews.com/berita= 119-bahaya-kemasan-plastik-html.

16. Kalsel, D. P. (2008). Riset Kesehatan dasar 2007. Banjarmasin: Dinkes Provinsi kalsel.

17. Koswara, S. (2006). Bahaya dibalik Kemasan Plastik. ebookpangancom.
18. Murti, B. (2003). Prinsip dan Metode Riset Epidemiologi. Yogyakarta: Gadjah Mada Universiy Press.

19. Notoatmodjo, 2007, Promosi Kesehatan dan Ilmu Perilaku, Jakarta, Rineka Cipta

20. Nurminah, M. (2002). Penelitian Sifat Berbagai Bahan Kemasan Plastik dan Kertas serta Pengaruhnya terhadap Bahan yang Dikemas. Medan: USU Digital Library. 